\title{
TRANSFORMASI DIGITAL TECHNOLOGY-ORGANIZATION- ENVIRONMENT (TOE) DAN INOVASI DIFUSI E-BUSINESS UNTUK UMKM YANG BERKELANJUTAN: MODEL KONSEPTUAL
}

\author{
${ }^{1}$ Eman Sulaiman, ${ }^{2}$ Cucu Handayani, ${ }^{3}$ Susi Widyastuti \\ ${ }^{1}$ STIE Cirebon, ${ }^{2,3}$ STIKOM POLTEK Cirebon \\ email: ${ }^{1}$ emans.aero@gmail.com, ${ }^{2,}$ de2handayani@gmail.com, ${ }^{3}$ miss_siwy@yahoo.com
}

\begin{abstract}
ABSTRAK
Transformasi digital adalah salah satu topik favorit saat ini. Topik ini mempengaruhi lingkungan ekonomi serta bisnis dan negara. Studi ini mengeksplorasi multidimensi konstruk TOE Framework, pengembangan dan penerapan teori RBVsehingga inovasi difusi diaplikasikan pada ebusiness dan ecommerce. Peran sentral dari transfornasi digital yang menjembatani konseptual model ini yang akan membuat UMKM dapat Sustainable Advantage untuk menghadapai industry 4.0 dan situasi pandemic era. Studi literature dengan membangun dan mengembangkan konsep. Tahap pertama dalam pemilihan literatur dilakukan dengan mencari makalah, jurnal, dan artikel berdasarkan kesesuaian kata kunci dengan judul atau abstrak yang telah ditentukan. Tahap kedua dilanjutkan dengan menghilangkan literatur yang tidak memenuhi kriteria inklusi dan kriteria eksklusi berdasarkan relevansi abstrak. Langkah ketiga adalah mengevaluasi karya sastra dengan membacanya secara utuh dan menilai kualitas karya sastra tersebut. Langkah terakhir adalah memilih literatur yang telah melewati tahap evaluasi dan penilaian kualitas. makalah ini membangun sebuah model dalam upaya untuk menutup kesenjangan pengetahuan yang ditemukan dalam penelitian sebelumnya. Dari tinjauan literatur, teori yang berkaitan dengan inovasi dan difusi E-bisnis, juga penciptaan nilai diperiksa untuk mengidentifikasi kesenjangan pengetahuan dalam pengukuran kinerja bisnis sebelumnya. Model multidimensi kemudian dikembangkan dengan inovasi tiga teori dan model, yaitu model TOE framework, transformasi digital, teori RBV dan keunggulan kompetitif yang berkelanjutan.
\end{abstract}

Kata kunci: TOE Framework, Transformasi Digital, theory RBV, Innovation Diffusion, Sustainable Advantage

\begin{abstract}
This study explores the multidimensional construct of the TOE Framework, the development and application of RBV theory so that diffusion innovation is applied to e-business and e-commerce. The central role of digital transformation is to bridge this conceptual model which will make MSMEs have a Sustainable Advantage to face industry 4.0 and the pandemic era situation. Study literature by building and developing concepts. The first stage in the selection of literature is done by searching for papers, journals, and articles based on the suitability of keywords with predetermined titles or abstracts. The second stage was continued by eliminating literature that did not meet the inclusion criteria and exclusion criteria based on the relevance of the abstract. The third step is to evaluate the literary work by reading it in its entirety and assessing the quality of the literary work. The final step is to select literature that has passed the evaluation and quality assessment stages. this paper builds a model in an attempt to close the knowledge gap found in previous research. From the literature review, theories related to innovation and diffusion of E-business, as well as value creation are examined to identify knowledge gaps in previous business performance measurement. The multidimensional model was then developed with the innovation of three theories and models, namely the TOE framework model, digital transformation, RBV theory and sustainable competitive advantage.
\end{abstract}


Keywords: TOE Framework, Digital Transformation, RBV theory, Innovation Diffusion, Sustainable Advantage

\section{PENDAHULUAN}

Transformasi digital mempengaruhi semua sektor masyarakat, khususnya ekonomi. Apalagi pada saat pandemic covid19 saat ini berdampak pada UMKM. Perusahaan sekarang diberi kesempatan untuk secara radikal mengubah model bisnis mereka dengan teknologi digital baru seperti jejaring sosial, seluler, big data, Internet, inovasi lain implementasi transformasi digital seperti epayment, ebusiness, ecommerce (Ayo et al., 2008; Kabir et al., 2015; Mendes et al., 2004) dan termutahir inovasi blockhain (Rot et al., 2020; Sujatha et al., 2020). Ini sebagian besar melibatkan perubahan operasi bisnis inti dan memodifikasi produk dan proses, serta struktur organisasi, karena UMKM sebagai organisasi sederhana harus menyiapkan praktik manajemen untuk melakukan transformasi kompleks ini (Priyono et al., 2020a). Akibatnya, masyarakat secara keseluruhan menghadapi perubahan radikal karena perkembangan teknologi digital dan implementasinya yang luas di semua pasar (Reis et al., 2018). Untuk menambah minat yang diperluas dari customer, organisasi menghadapi persaingan yang lebih keras karena globalisasi (Al Idrus, 2008) dan menempatkan tekanan untuk go digital sebelum orang lain melakukannya, mencari untuk bertahan hidup dan mencapai manfaat kompetitif (Ismail et al., 2017).

Dalam penelitian ini, kami mempelajari perubahan inovasi model bisnis yang disebabkan oleh internet industri (juga disebut 'industri 4.0') atau lebih umum oleh transformasi ekonomi ke teknologi digital ('digitalisasi'). Kami mengembangkan model perubahan yang disebabkan oleh model bisnis seiring dengan perkembangan industri digital. Model tersebut menghubungkan perubahan dalam komponen model bisnis dan keterkaitannya dengan karakteristik spesifik dari teknologi digital dan difusi inovasi. Sejalan dengan (Michael, 1980) keputusan teknologi strategis perusahaan bergantung pada karakteristik industri misalnya persaingan, manajemen hubungan pelanggan dan pemasok, dan pemerintah di samping tahapan siklus hidup industri.

Kurangnya pengetahuan transformasi digital untuk UMKM baik secara teoritis dan implementasi menyebabkan ketertinggalan infromasi issue mutahir megenai keberlanjutan pertumbuhan dan membuat UMKM belum kompetitif (Johnson \& Schaltegger, 2016; Priyono et al., 2020b). Dengan latar belakang tersebut peneliti mencoba meramu konsep 
Transformasi Digital Technology-Organization-Environment (TOE) Dan Inovasi Difusi EBusiness untuk pertumbuhan UMKM yang kompetitif dan berkelanjutan.

\section{KAJIAN PUSTAKA}

\section{Digital Transformation}

Meskipun Digital Transformation adalah topik diskusi yang populer saat ini, ide-ide produk, layanan, dan media digital sudah dipahami dengan baik pada 1990-an dan 2000-an (Auriga, 2016). Berbagai definisi transformasi digital dapat ditemukan dalam literatur. Konsep transformasi digital dibentuk oleh penggabungan lingkungan TI pribadi dan perusahaan dan merangkum efek transformasi teknologi digital baru seperti sosial, seluler, analitis, teknologi cloud dan Internet of Things (White, 2008). Dalam arti yang lebih luas, transformasi digital dihadirkan sebagai integrasi teknologi digital dan proses bisnis dalam ekonomi digital (Liu, D.Y. et al., 2011). Roadmap Transformasi digital menurut (Ziyadin et al., 2020) adalah: Digital reality, Digital aspiration, Digital potential, Digital fit, Digital integration.

\section{Inovasi difusi teknologi}

Teori Difusi Teknologi, Berasal dari (E. M. Rogers, 1962), teori ini terkenal dan populer dalam studi sebelumnya tentang difusi inovasi. Untuk teknologi yang akan diadopsi, Rogers membagi proses adopsi menjadi lima tahap; kesadaran, minat, evaluasi, percobaan, dan adopsi. Untuk tahap kesadaran, Karena teori difusi teknologi berfokus terutama pada individu, pekerjaan lebih lanjut dilakukan oleh (De Pietro et al., 1990) dalam mengembangkan kerangka kerja untuk mendapatkan pemahaman tentang adopsi teknologi dalam organisasi. Berdasarkan tiga konteks di atas, Tornatzky dan Fleischer (1990) selanjutnya membangun model TOE untuk digunakan dalam evaluasi adopsi teknologi. Model tersebut sesuai dengan (E.M. Rogers, 1983) tentang teori difusi inovasi dalam organisasi (Alam, 2018).

\section{TOE Framework}

Berdasarkan konsep TOE FRAMEWORK Tiga konteks kunci yang diakui kerangka TOE, yaitu konteks teknologi, konteks organisasi, dan konteks lingkungan. Konteks teknologi mewakili teknologi yang ada dan keselarasan teknologi terbaru yang relevan dengan organisasi. Konteks organisasi berkaitan dengan ukuran dan jangkauan organisasi. Konteks lingkungan merupakan arena dimana perusahaan menjalankan usahanya. Kerangka kerja TOE menjelaskan adopsi inovasi dan memberikan kerangka kerja analitis yang berguna 
untuk mempelajari penerimaan dan asimilasi berbagai jenis teknologi. Kerangka TOE kompatibel dengan konsep teori inovasi dalam organisasi.

Ada beberapa alasan mengapa kerangka TOE dipilih sebagai kerangka teoritis untuk mendukung penelitian ini. Pertama, framework TOE cocok untuk mempelajari adopsi dalam konteks UMKM. Kedua, kerangka TOE memiliki landasan teori yang jelas dan dukungan empiris yang konsisten. Ketiga, TOE konsisten dengan teori inovasi TI di tingkat organisasi lain, yang memperkuat dan meningkatkan kekuatan penjelas kerangka kerja. Keempat, TOE dipandang sebagai framework yang komprehensif sehingga dapat digunakan untuk mengkaji adopsi teknologi informasi. Kelima, ketiga konteks (teknologi, organisasi, dan lingkungan) menawarkan keunggulan dibandingkan model adopsi lainnya karena kerangka TOE memberikan pandangan yang komprehensif tentang faktor-faktor yang mempengaruhi keputusan adopsi TI (Handayani \& Mahendrawathi, 2019). TI berperan penting pada transformasi digital perusahaan telah menjadi tren perkembangan yang tak terhindarkan dan salah satu kekuatan pendorong utama yang mendorong pembangunan berkelanjutan UMKM. Namun, karena banyak kendala beban keuangan, ambang teknis, dan kekurangan bakat, transformasi digital telah menjadi tugas yang menantang bagi Usaha Kecil dan Menengah (UKM) wirausaha.

\section{Teori RBV dalam Difusi E-Bisnis}

Dalam menentukan bagaimana penggunaan E-business mempengaruhi kinerja bisnis, tinjauan literatur dilakukan mengenai tahap pasca adopsi E-business dengan melihat teori dan model sebelumnya seperti Evolutionary Game Theory (Kauffman, Wang \& Miller, 2002), IS model seleksi penilaian (Myers, Kappleman \& Prybutok, 1997), model Data Envelopment Analysis (DEA) dan teori RBV. Namun, mengingat organisasi tersebut dipilih sebagai unit analisis, teori dan model paling terkenal yang terkait dengan penelitian ini adalah teori permainan evolusioner (Kauffman, Wang \& Miller, 2002), dan teori RBV (Zhu \& Kraemer, 2005; dan Peteraf, 1993).

\section{Sustainable Advantage}

Model keunggulan kompetitif awalnya disebutkan oleh (Alderson, 1957), yang berpendapat bahwa setiap organisasi harus mengeksplorasi dan menemukan strategi apa pun yang dapat melindungi posisi untuk bertahan dalam tantangan pasar. Namun, konsep keunggulan kompetitif banyak ditemukan dalam karya-karya (Porter, 1990) yang mengangkatnya sebagai salah satu sarjana top di bidang manajemen strategis. Dengan kata lain, keunggulan kompetitif dipahami sebagai kemampuan organisasi untuk merumuskan dan mempertahankan strategi yang tidak dapat dicapai di depan para pesaing ( $\mathrm{Li}$ et al., 2009) di 
tingkat organisasi (W. et al., 2011) Selain itu, situs internet disepakati sebagai taktik persaingan yang vital justru dalam industri jasa karena penggunaan internet sangat penting dalam menarik pelanggan potensial baru (Sidek et al., 2020).

\section{METODE PENELITIAN}

Penelitian ini diawali dengan mengkaji penelitian sebelumnya yang berkaitan dengan anteseden adopsi inovasi difusi dan tranformasi digital pada proses bisnis yang melibatkan orang, budaya dan struktur organisasi serta melihat gap/fenomena dari literatur yang ada. Temuan penelitian sebelumnya dan analisis kesenjangan disatukan dengan masalah yang diidentifikasi dalam penelitian ini. Dilanjutkan dengan melakukan analisis dan sintesa literature review terkait transformasi digital dalam manajemen proses bisnis, difusi inovasi dan framework TOE, dan UMKM. Metode yang digunakan dalam penelitian ini adalah Literature Review Paper (LRP). Penulis menggunakan dua database untuk mencari literatur yaitu Emerald Insight (https://www.emeraldinsight.com) dan ScienceDirect (https://sciencedirect.com).

Tahap pertama dalam pemilihan literatur dilakukan dengan mencari makalah, jurnal, dan artikel berdasarkan kesesuaian kata kunci dengan judul atau abstrak yang telah ditentukan. Tahap kedua dilanjutkan dengan menghilangkan literatur yang tidak memenuhi kriteria inklusi dan kriteria eksklusi berdasarkan relevansi abstrak. Langkah ketiga adalah mengevaluasi karya sastra dengan membacanya secara utuh dan menilai kualitas karya sastra tersebut. Langkah terakhir adalah memilih literatur yang telah melewati tahap evaluasi dan penilaian kualitas. Indikator model konseptual dikembangkan berdasarkan kerangka TO, inivasi difusi digital, transformasi digital, teori rbv, dan sustainable advantage. Tahapan penelitian diilustrasikan pada Gambar 1 berikut ini:

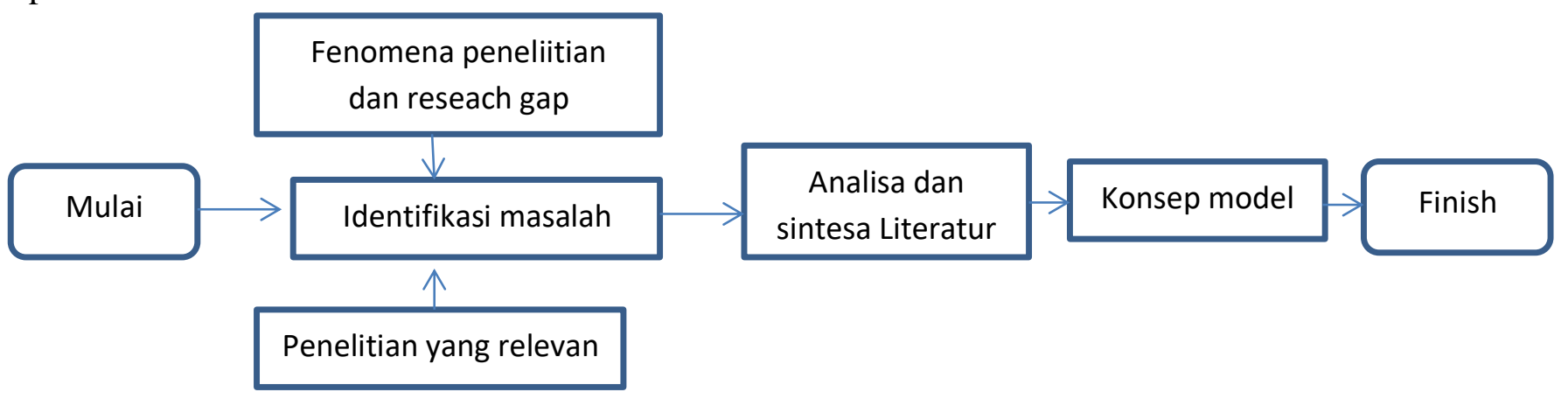

Gambar 1. Tahapan penelitian 


\section{HASIL PENELITIAN DAN PEMBAHASAN}

\section{Hasil Penelitian}

Hasil sintesis dan analisis literatur terkait penelitian transformasi digital pada UMKM dan aspek difusi inovasi manajemen proses bisnis pada penelitian sebelumnya agar UMKM bisa kompetitive berkelanjutan mmenghasilkan model konseptual yang diusulkan dijelaskan pada Gambar 2 berikut:

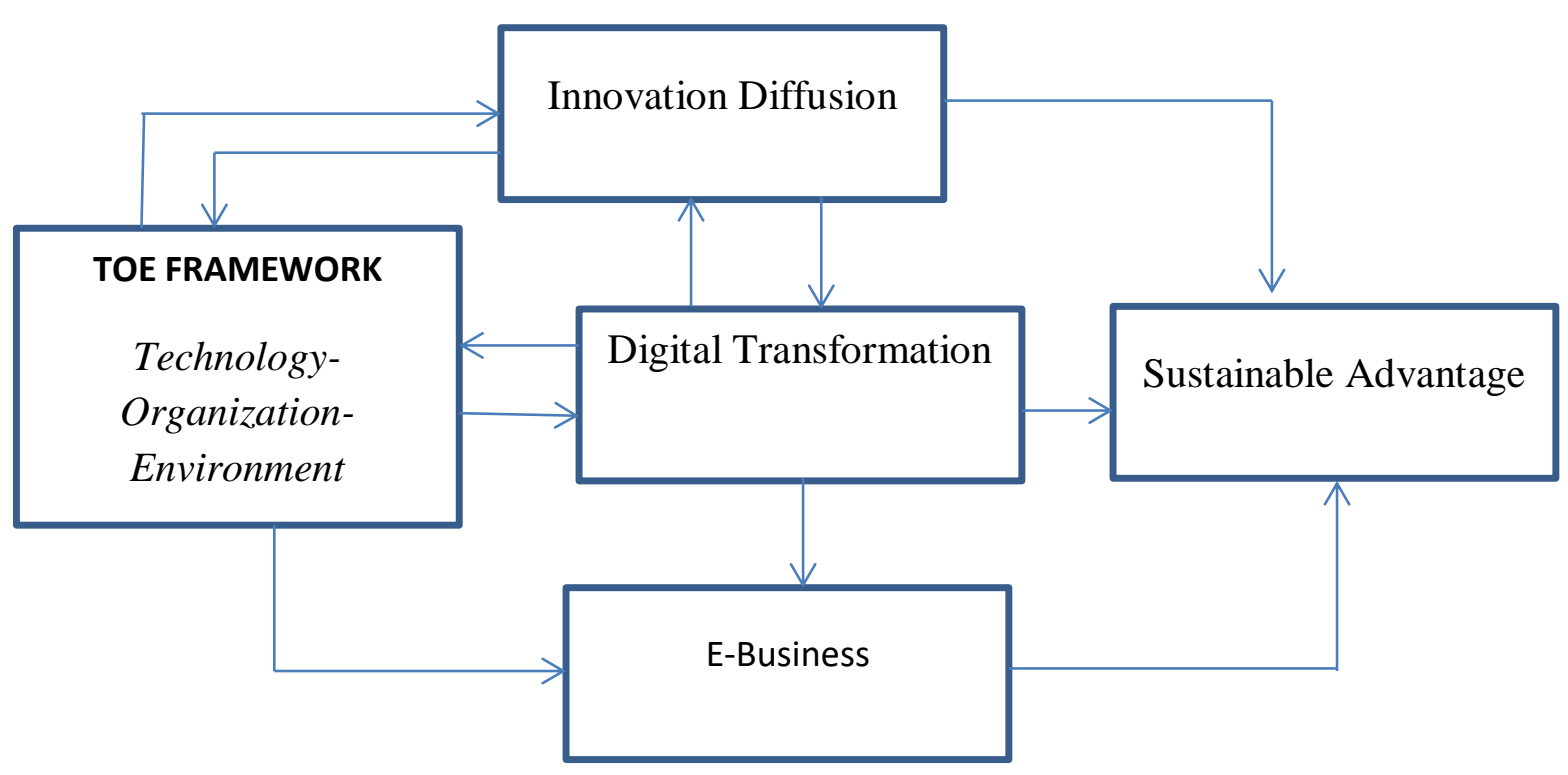

Gambar 2. Purporsed Conceptual Model Framework

Berdasarkan studi sebelumnya mengenai TOE Framework (Handayani \& Mahendrawathi, 2019) mengenai pengembangan model Anteseden dan Manajemen Proses Bisnis Non-Teknis Kemampuan Implementasi Media Sosial untuk Mikro, Kecil dan Usaha Menengah dan konsep Perspektif Terintegrasi Kerangka TOE dan Difusi Inovasi (Chiu et al., 2017), studi (Alam, 2018) model multidimensi mengenai eBusiness usage, selanjtunya penelitian road map digital transformation (Schallmo et al., 2017) dan Digital Transformation in Business (Ziyadin et al., 2020), dari model konseptual tersebut dibangunlah proposisi. Proposisi adalah pernyataan tentang konsep yang dapat dinilai benar atau salah jika dihubungkan dengan fenomena yang diobservasi (Kinney, 1986), sedangkan menurut (Moh. Nazir, 1983) proposisi adalah peryataan tentang sifat dari realita, sehingga proposisi masih berada pada tataran konsep maka dapat diajukan proposi penelitian sebagai berikut: 
P1: TOE Framework yang terdiri dari 3 unsur (Teknologi, Organisasi dan lingkungan) merupakan pijakan dasar transformasi digital memoderasi hubungan tersebut sehingga UMKM akan sustainable advantage.

P2. TOE Framework yang terdiri dari 3 unsur (Teknologi, Organisasi dan lingkungan) merupakan perpaduan yang unik dan komplek dengan yang dimediasikan oleh tindakan berinovasi dan gabunganya (fusion) sehingga UMKM akan sustainable advantage.

P3. TOE Framework yang terdiri dari 3 unsur (Teknologi, Organisasi dan lingkungan) merupakan perpaduan yang utuh untuk sebuah bisnis secara eletronik (ebusiness) sebagai mediasinya sehingga UMKM akan sustainable advantage.

Kesimpulan Analisis pengukuran dimensi dan indicator masing varibel dapat dilihat pada tabel 1 berikut:

\begin{tabular}{|c|c|c|c|}
\hline No & Varibel & Sumber & Indikator \\
\hline \multirow[b]{2}{*}{1} & TOE FRAMEWORK & & \\
\hline & $\begin{array}{c}\text { External Task Environment } \\
\text { Organization } \\
\text { Technology }\end{array}$ & $\begin{array}{l}\text { (Chiu et al., } \\
\text { 2017; } \\
\text { Handayani \& } \\
\text { Mahendrawathi, } \\
\text { 2019) }\end{array}$ & $\begin{array}{l}\text { - Industry Characteristics and } \\
\text { - Market Structure } \\
\text { - Technology Support Infrastructure } \\
\text { - Government Regulation } \\
\text { - Formal and Informal Linking } \\
\text { - Structures } \\
\text { - Communication Processes } \\
\text { - Size } \\
\text { - slack } \\
\text { - Availability } \\
\text { - Characteristics }\end{array}$ \\
\hline 2 & Transformasi Digital & (İnel, 2019) & $\begin{array}{l}\text { - Digital Infrastructure } \\
\text { - Investments and Access to Finance } \\
\text { - Supply and Demand of Digital Skills } \\
\text { - E-Leadership } \\
\text { - Entrepreneurial Culture }\end{array}$ \\
\hline
\end{tabular}

\section{E-BUSINESS}

- Profitable

3

Impact On Financial
- Increase the Return on Investment (ROI)

(Alam, 2018) • Contribute to the revenue

- Operational cost reduction

- Reduced the cost of acquiring a new 
customer

- Reduced the cost for customer relationship management

- Reduced the procurement costs

- Reduced the inventory costs

- Increase on-time delivery of services

- Reduce the number of problems with customer reservations processing

Impact On Internal Business Process

Impact On Customer

Impact On Learning And Growth

- Reduce the number of E-business issues reported in internal audit report

- Reduce the number of E-business issues reported in external audit report

- Increased staff productivity

- Imporved coordination with suppliers

- Online customers repeat their web purchases

- Reduced the number of customer complaints

- Generate new customers

- Increase sales

- Widened sales area

- Improved customer service

- Nature And Introduction Of An Innovative Idea,

(Everett M - Organizational Capacity To

4 Innovation Diffution Rogers \& Scott, 1997) Acquire, Assimilate, Transform And Exploit An Innovation

- Rates Of Innovation Facilitation And Adoption.

- Rare

- Valuable

$5 \quad$ Sustainable Advantage $\quad$ (Barney, 2001)

- Inimitable

- Non Tradable

- Non substituable

Tabel 1. Measurement indicator variabel

\section{Pembahasan}

Suatu bisnis agar bisa bertahan secara berkelanjutan saat ini harus bisa mengimbangi pergeseran teknologi di semua bidang, tak terkecuali urusan eknomi dan UMKM. Tetapi semua harus disesuaikan dengan kemampuan organisasi dan dilakukan dengan bertahap, continue dan sustainable. Sesuai dengan penelitian (Priyono et al., 2020b) bahwa 
transformasi digital UKM yang beroperasi di industri kreatif tidak serta merta melibatkan transformasi model bisnis yang radikal; transformasi dapat diimplementasikan secara bertahap dan pada tingkat perubahan yang berbeda.

\section{KESIMPULAN DAN IMPLIKASI}

Seperti semua model, kerangka model bisnis digitalisasi dapat diperluas ke berbagai arah. Data lebih lanjut tentang inovasi model bisnis dapat menciptakan hubungan baru antar elemen. Mungkin yang lebih penting, model dapat ditingkatkan presisinya dengan sehubungan dengan detail tentang digitalisasi. Misalnya, model dapat memberikan informasi tentang batasan seperti karakteristik saluran, jumlah data, persyaratan waktu nyata, dan pengaruhnya terhadap komponen model lainnya. Model tersebut harus diuji sehubungan dengan kegunaan bagi peneliti inovasi dalam mengembangkan lebih lanjut dasar-dasar teoritis lapangan. Mereka mungkin secara khusus mengarah pada studi yang lebih baik tentang hubungan sebab akibat dalam kerangka model bisnis. Jaringan lengkap atau optimalisasi seluruh sistem produksi belum terjadi. Kami berharap model seperti yang disajikan di sini menambah kreativitas para inovator pada umumnya dan inovator model bisnis pada khususnya untuk memanfaatkan potensi digitalisasi secara maksimal.

Implikasi secara teoritis dapat menambah body of knolwadge mengenai transformasi digital pada ebusiness dan inovasi difusi yang didasarkan oleh TOE Framework agar UMKM dapat terus berkelanjutan.

\section{DAFTAR PUSTAKA}

Al Idrus, S. (2008). Solusi Strategis Organisasi Bisnis Menghadapi Persaingan di Era Global. IQTISHODUNA.

Alam, S. (2018). E-Business Usage and Business Performance: Development of Multidimensional E-Value Model. Asia Pacific Journal of Advanced Business and Social Studies, 4(2), 64-78. https://doi.org/10.25275/apjabssv4i2bus8

Alderson, W. (1957). Marketing Behavior and Executive Action: A Functionalist Approach to Marketing. Richard D. Irwin Inc,.

Ayo, C. K., Adebiyi, A. A., Afolabi, I. T., \& Ekong, U. O. (2008). A framework for ecommerce implementation: Nigeria a case study. Journal of Internet Banking and Commerce, 13(2), 1-12. 
Barney, J. B. (2001). Resource-based theories of competitive advantage: A ten-year retrospective on the resource-based view. Journal of Management, 27(6), 643-650. https://doi.org/10.1177/014920630102700602

Chiu, C.-Y., Chen, S., \& Chen, C.-L. (2017). An integrated perspective of TOE framework and innovation diffusion in broadband mobile applications adoption by enterprises. International Journal of Management, Economics and Social Sciences (IJMESS), 6(1), 14-39.

De Pietro, R., Wiarda, E. \&, \& Fleischer, M. (1990). The context for change: Organization, technology and environment (L. G. T. \& M. Fleischer (ed.); eds. The P). Lexington Books.

Handayani, S. F., \& Mahendrawathi, E. R. (2019). Antecedent and business process management non-technical capabilities in social media implementation for micro, small and medium enterprises: A conceptual model. Procedia Computer Science, 161, 11141121. https://doi.org/10.1016/j.procs.2019.11.223

İnel, M. (2019). An empirical study on measurement of efficiency of digital transformation by using data envelopment analysis. Management Science Letters, 9(4), 549-556.

Ismail, M. H., Khater, M., \& Zaki, M. (2017). Digital business transformation and strategy: What do we know so far. Cambridge Service Alliance, 10, 1-35.

Johnson, M. P., \& Schaltegger, S. (2016). Two decades of sustainability management tools for SMEs: How far have we come? Journal of Small Business Management, 54(2), 481505.

Kabir, M. A., Saidin, S. Z., \& Ahmi, A. (2015). Adoption of e-payment systems: a review of literature. International Conference on E-Commerce, 112-120.

Li, H., V., L., M., S., J., W., \& E., C. (2009). Competitiveness factors: A study of the real estate market in China. Construction Management and Economics, 27(1), 567-569.

Liu, D.Y., Chen, S. W., \& Chou, T. C. (2011). Resource fit in digital transformation: lessons learned from the CBC Bank global e-banking project. Management Decision, 49(10), 1728-1742. https://doi.org/https://doi.org/10.1108/00251741111183852

Mendes, M. J., Suomi, R., \& Passos, C. (2004). Digital communities in a networked society: e-commerce, e-business and e-government (Vol. 139). Springer Science \& Business Media.

Michael, E. P. (1980). Competitive strategy: Techniques for analyzing industries and competitors. Editorial Free Pr, ISBN, 13, 9780029253601.

Porter, M. E. (1990). New global strategies for competitive advantage. Planning Review, 
18(3), 4-14. https://doi.org/10.1108/eb054287

Priyono, A., Moin, A., \& Putri, V. N. A. O. (2020a). Identifying digital transformation paths in the business model of smes during the covid-19 pandemic. Journal of Open Innovation: Technology, Market, and Complexity, 6(4), 1-22. https://doi.org/10.3390/joitmc6040104

Priyono, A., Moin, A., \& Putri, V. N. A. O. (2020b). Identifying digital transformation paths in the business model of SMEs during the COVID-19 pandemic. Journal of Open Innovation: Technology, Market, and Complexity, 6(4), 104.

Reis, J., Amorim, M., Melão, N., \& Matos, P. (2018). Digital transformation: a literature review and guidelines for future research. World Conference on Information Systems and Technologies, 411-421.

Rogers, E. M. (1962). Diffusion of innovations (ist). Free Press.

Rogers, E.M. (1983). Diffusion of Innovations. (3rd ed.). The Free Press.

Rogers, Everett M, \& Scott, K. L. (1997). The diffusion of innovations model and outreach from the National Network of Libraries of Medicine to Native American communities. Retrieved March, 22, 2006.

Rot, A., Sobińska, M., Hernes, M., \& Franczyk, B. (2020). Digital transformation of public administration through blockchain technology. In Towards Industry 4.0-Current Challenges in Information Systems (pp. 111-126). Springer.

Schallmo, D., Williams, C. A., \& Boardman, L. (2017). Digital transformation of business models-best practice, enablers, and roadmap. International Journal of Innovation Management, 21(8), 1-17. https://doi.org/10.1142/S136391961740014X

Sidek, S., Rosli, M. M., Khadri, N. A. M., Hasbolah, H., Manshar, M., \& Abidin, N. M. F. N. Z. (2020). Fortifying Small Business Performance Sustainability in the Era of Ir 4.0: EMarketing As a Catalyst of Competitive Advantages and Business Performance. Journal of Critical Reviews, 7(13), 2143-2155.

Sujatha, R., Navaneethan, C., Kaluri, R., \& Prasanna, S. (2020). Optimized Digital Transformation in Government Services with Blockchain. In Blockchain Technology and Applications (pp. 79-100). Auerbach Publications.

W., W.-C., Chien-Hung, L., \& Ying-Chien, C. (2011). Types of competitive advantage and analysis. International Journal of Business and Management, 6(5), 100 - 104.

White, H. C. (2008). Identity and Control: How Social Formations Emerge (2nd ed.). Princeton University Press.

Ziyadin, S., Suieubayeva, S., \& Utegenova, A. (2020). Digital Transformation in Business. In 
Lecture Notes in Networks and Systems (Vol. 84). Springer International Publishing. https://doi.org/10.1007/978-3-030-27015-5_49 